\title{
Development of a validation algorithm for 'present on admission'
} flagging

\author{
Terri J Jackson*1, Jude L Michel ${ }^{1}$, Rosemary Roberts ${ }^{1}$, Jennie Shepheard ${ }^{2}$, \\ Diana Cheng ${ }^{3}$, Julie Rust ${ }^{4}$ and Catherine Perry ${ }^{2}$
}

\begin{abstract}
Address: ${ }^{1}$ Australian Centre for Economic Research on Health (ACERH), School of Medicine, University of Queensland, Brisbane, Australia, ${ }^{2}$ Victorian Department of Health; 50 Lonsdale Street, Melbourne, Victoria, Australia, ${ }^{3}$ Health Information Management, La Trobe University, Victoria, Australia and ${ }^{4}$ National Centre for Classification in Health (NCCH), Faculty of Health Sciences, The University of Sydney, Lidcombe New South Wales, Australia

Email: Terri J Jackson* - t.jackson@uq.edu.au; Jude L Michel - judith.michel@uq.edu.au; Rosemary Roberts - rroberts@aapt.net.au; Jennie Shepheard - Jennie.Shepheard@dhs.vic.gov.au; Diana Cheng - D.Cheng@latrobe.edu.au; Julie Rust - J.Rust@usyd.edu.au; Catherine Perry - Catherine.Perry@dhs.vic.gov.au

* Corresponding author
\end{abstract}

Published: I December 2009

BMC Medical Informatics and Decision Making 2009, 9:48 doi:10.1/186/1472-6947-9-48

This article is available from: http://www.biomedcentral.com/1472-6947/9/48

(C) 2009 Jackson et al; licensee BioMed Central Ltd.

This is an Open Access article distributed under the terms of the Creative Commons Attribution License (http://creativecommons.org/licenses/by/2.0), which permits unrestricted use, distribution, and reproduction in any medium, provided the original work is properly cited.
Received: 28 January 2009

Accepted: I December 2009

\begin{abstract}
Background: The use of routine hospital data for understanding patterns of adverse outcomes has been limited in the past by the fact that pre-existing and post-admission conditions have been indistinguishable. The use of a 'Present on Admission' (or POA) indicator to distinguish pre-existing or co-morbid conditions from those arising during the episode of care has been advocated in the US for many years as a tool to support quality assurance activities and improve the accuracy of risk adjustment methodologies. The USA, Australia and Canada now all assign a flag to indicate the timing of onset of diagnoses. For quality improvement purposes, it is the 'not-POA' diagnoses (that is, those acquired in hospital) that are of interest.
\end{abstract}

Methods: Our objective was to develop an algorithm for assessing the validity of assignment of 'not-POA' flags. We undertook expert review of the International Classification of Diseases, 10th Revision, Australian Modification (ICD-I0-AM) to identify conditions that could not be plausibly hospital-acquired. The resulting computer algorithm was tested against all diagnoses flagged as complications in the Victorian (Australia) Admitted Episodes Dataset, 2005/06. Measures reported include rates of appropriate assignment of the new Australian 'Condition Onset' flag by ICD chapter, and patterns of invalid flagging.

Results: Of 18,418 diagnosis codes reviewed, 93.4\% $(n=17,195)$ reflected agreement on status for flagging by at least 2 of 3 reviewers (including 64.4\% unanimous agreement; Fleiss' Kappa: $0.6 \mathrm{I}$ ). In tests of the new algorithm, $96.14 \%$ of all hospital-acquired diagnosis codes flagged were found to be valid in the Victorian records analysed. A lower proportion of individual codes was judged to be acceptably flagged $(76.2 \%)$, but this reflected a high proportion of codes used $<5$ times in the data set (789/1035 invalid codes).

Conclusion: An indicator variable about the timing of occurrence of diagnoses can greatly expand the use of routinely coded data for hospital quality improvement programmes. The data-cleaning instrument developed and tested here can help guide coding practice in those health systems considering this change in hospital coding. The algorithm embodies principles for development of coding standards and coder education that would result in improved data validity for routine use of non-POA information. 


\section{Background}

On $1^{\text {st }}$ October 2007 acute care hospitals in the United States commenced reporting of the 'present on admission' (POA) indicator to distinguish secondary conditions that are present on admission from those arising during the hospital episode. From January 2008 the indicator has been included in the processing of Medicare claims [1]., but its use has been advocated for many years to support quality assurance activities and improve risk adjustment methodologies [2,3]. From October 2008 selected conditions coded as not present on admission do not result in higher payments from Medicare [4].

The quality of routinely collected diagnosis data has become increasingly important, as more clinicians, managers and funders call on these data to answer important questions about health services [5]. While logic edits are quite common in this field $[6,7]$, clinical edits (that apply clinical knowledge to remove implausible coding combinations) are less common. The use of routine hospital data for understanding patterns of adverse outcomes has been limited by the fact that pre-existing and post-admission conditions have been indistinguishable [8-10].

Support for the POA indicator has emerged through US studies which have demonstrated that it improves routine data in various ways [11-18].

Since the mid-1980s, the Victorian Department of Human Services (VDHS) has required all routinely abstracted diagnosis data to be assigned one of four 'prefixes': ' $P$ ' for primary diagnoses occasioning the admission and treated during the episode, 'A' for associated pre-existing diagnoses which may have had an impact on treatment even though not actively treated, ' $\mathrm{M}$ ' for neoplasm morphology codes, and ' $\mathrm{C}$ ' for diagnoses arising and treated during the current episode [19]--that is 'not present on admission'.

For application of the ' $\mathrm{C}$ ' prefix (indicating a 'complication'), the coder must ascertain that there was no evidence of the condition existing prior to admission; the C-prefix is used only for a diagnosis arising after admission. This distinguishes incident complications (arising during the current episode of in-hospital care) from those treated in a subsequent episode [20].

In 2007, all Australian states and territories agreed to the adoption of a national 'Condition Onset' flag for diagnoses in the National Inpatient Minimum Dataset, commencing collection in July 2008. Guidance on national condition onset flag assignment has been published in the Australian Coding Standards for ICD-10-AM, 6th edition [21] and broadly follows the Victorian guidelines.

The new national indicators reported in the US differ from those reported in Australia with flags for 'Unknown' and
'Clinically undetermined' in addition to those for 'present on admission' and 'not present on admission'[1]. A list of codes is also published in the ICD-9-CM Official Guidelines for Coding and Reporting which are exempt from POA reporting in the US; these codes are predominantly from the 'factors influencing health status' and 'external cause' chapters [22] of the ICD. In comparison, there are no exempt codes in Australia and a default of 'present on admission' is mandated for conditions where onset is unknown [21].

Canada has adopted a set of 10 'Diagnosis Type' flags, with a 'most responsible diagnosis', external cause, obstetric, and transfer-related markers, in addition to those used in Australia [23]. The national standard for their 'Diagnosis Type 2 Post-Admit Comorbidity' flag specifies 6 sets of excluded codes: neoplasms, diabetes, hypertension, HIV, chronic pulmonary disease, and problems related to medical facilities and other care [24]. When these code sets from the Canadian adaptation of ICD-10 [25] are translated into the Australian version of ICD, they total 962 codes that are disallowed by an edit program used by the Canadian Institute for Health Information (CIHI).

In Victoria, routine diagnosis coding has been validated through coding audits since the mid-1990's [26,27], but assignment of the Victorian prefixes has not been studied. A formal audit (re-abstraction) study including the diagnosis-onset flag was conducted in 2008 as part of the VDHS inpatient data audit program, but has not yet been published [28].

In 2004, VDHS undertook a review of the entire ICD-10AM classification to clarify which codes could plausibly be assigned to each of the three prefixes (morphologies of neoplasm forming its own distinct part of the classification). No use has been made of this editing algorithm, in part because of the lack of validation of the codes selected by the single reviewer [29]. Subsequently, a warning edit including approximately 2,700 diagnosis codes judged as unlikely to have arisen during a hospital admission has been adopted in Victoria, and alerts hospitals when these codes are erroneously flagged as complications [30].

As more jurisdictions adopt 'present on admission' (POA) or similar timing markers for diagnoses, the need for better measures of data quality becomes apparent. Glance et al. $[12,13]$ validated the POA indicator in Californian hospitals for a range of chronic conditions and reported accuracy between $90-100 \%$. A data cleaning algorithm to reject chronic or congenital conditions flagged as present on admission and exclude them from programs monitoring patient safety would reduce the problem of overcounting of events that has previously been noted in automated surveillance systems [31]. 
Our goal was to review all 18,418 codes in ICD-10-AM, 4 th edition [32] to develop a code set (and computerised algorithm) that could be used by hospitals and health authorities to 'clean' flagged diagnosis data, particularly focussing on codes for slow-developing, chronic and congenital conditions that would never be 'hospital acquired'. The algorithm was also developed as an educational tool for coder training and future coding audit.

\section{Methods}

Three health information managers on the team (JM, RR \& JR) completed a survey form to independently evaluate the validity of each ICD-10-AM code for flagging as a diagnosis that might arise during a hospital admission. The draft national guidance, since adopted [21], was used to inform judgements about whether the diagnosis was considered suitable for flagging as non-POA or 'hospitalacquired'.

In the absence of a gold standard against which to compare judgments, a criterion of 2/3 consonant answers was considered sufficient to classify the flagging of the diagnosis as valid or invalid. Reviewers were also given categories for 'Warning' (the code might be used in particular circumstances, but frequent usage would warrant a 'warning' to data managers), and 'don't know' (where the reviewer felt their clinical understanding was not sufficient to make a reliable judgement). These two categories were analysed together, as both indicated uncertainty about assigning a clear include/exclude status. Agreement amongst reviewers was assessed using an online tool to calculate Fleiss' Kappa [33].

Clinician review of codes to be used in the parallel development of a grouping system for hospital-acquired diagnoses [34] identified 61 additional warning codes that were incorporated into the exclusion algorithm.

The algorithm (written in SAS ${ }^{\mathrm{TM}}$ coding, see Additional files 1 and 2) was then used to estimate the rate of invalid flagging in the 2005/06 Victorian Admitted Episodes Dataset (VAED) of 2,031,666 de-identified patient episodes from Victorian public and private hospitals. Data custodians waived formal ethical review as the study was a methodological one using de-identified patient data.

\section{Results}

Table 1 shows the distribution of codes by levels of agreement amongst reviewers. Of 18,418 diagnosis codes reviewed, $93.4 \%(n=17,195)$ reflected agreement on status for flagging by at least 2 of the 3 reviewers (including $64.4 \%$ unanimous agreement). The remaining $6.6 \%$ were a mixture of 'include/warning', 'exclude/warning', 'include/exclude' disagreements and 'don't know' responses that were assigned to a 'warning' class. The Fleiss' Kappa score for agreement amongst reviewers was .61 , where .70 is conventionally taken to be adequate agreement. A total of 10,567 codes (57.4\%) were designated invalid as hospital-acquired conditions (including $0.03 \%$ proposed by the clinical panel). The 1,001 codes designated as 'warning' codes (to be monitored to ensure they are used appropriately) have been combined with the 1,223 codes on which agreement could not be reached for the current version.

Table 2 breaks down the codes nominated for exclusion into their chapters in the ICD, reporting the proportion of codes in the chapter recommended for exclusion. All codes in three chapters of the ICD: 2 (Neoplasms), 17 (Congenital anomalies) and Appendix A (Morphologies of neoplasms), were recommended for exclusion. A further six chapters had more than $50 \%$ of codes recommended for exclusion: 21 (Factors influencing health status) 93.3\%, 13 (Musculoskeletal) 60.4\%, 4 (Endocrine) 59.8\%, 11 (Digestive system) 57.8\%, 5 (Mental and behavioural) 57.1, and 20 (External causes of morbidity) 51.9\%.

Analysis of the sources of greatest uncertainty amongst reviewers is presented in Table 3. The highest number of mixed response codes was found in the External Cause and the Musculoskeletal System chapters (Chapters 20 and 13). As a proportion of codes in the chapter, those relating to Anaemia and Other Blood Diseases (Chapter 3), Infectious and Parasitic Diseases (Chapter 1), and Nervous System (Chapter 6) resulted in the greatest uncertainty amongst our reviewers.

Table I: Proportion of codes with substantial reviewer agreement

\begin{tabular}{|c|c|c|c|c|c|}
\hline & Yes/Include & No/Exclude & Warn/Include rarely & TOTAL & $\%$ \\
\hline 3 Reviewers Agree & 3752 & 8102 & 6 & 11860 & $64.4 \%$ \\
\hline 2 Reviewers Agree & 1936 & 2404 & 995 & 5335 & $29.0 \%$ \\
\hline Mixed disagree/don't know & -- & -- & 1223 & 1223 & $6.6 \%$ \\
\hline Further exclusions suggested by clinical panel & -- & 61 & -61 & 0 & \\
\hline \multirow[t]{2}{*}{ Total } & 5688 & 10567 & 2163 & 18418 & $100.0 \%$ \\
\hline & $30.9 \%$ & $57.4 \%$ & $I I .7 \%$ & $100.0 \%$ & \\
\hline
\end{tabular}


Table 2: ICD-I0-AM Chapters with code numbers excluded in algorithm

\begin{tabular}{|c|c|c|c|c|c|}
\hline Chapter & Code group & & Algorithm exclusions & $\begin{array}{r}\mathrm{N} \text { of } \\
\text { codes in chapter }\end{array}$ & $\%$ chapter excluded \\
\hline Chapter I & $A B$ & Infectious and parasitic disease & 269 & 766 & 35.1 \\
\hline Chapter 2 & $C / D$ & Neoplasms & 790 & 790 & 100.0 \\
\hline Chapter 3 & part $D$ & Anaemia \& other blood diseases & 54 & 164 & 32.9 \\
\hline Chapter 4 & $\mathrm{E}$ & Endocrine & 274 & 458 & 59.8 \\
\hline Chapter 5 & $\mathrm{~F}$ & Mental/behavioural & 256 & 448 & 57.1 \\
\hline Chapter 6 & G & Nervous system & 114 & 387 & 29.5 \\
\hline Chapter $7 / 8$ & $\mathrm{H}$ & Eye \& ear & 75 & 372 & 20.2 \\
\hline Chapter 9 & 1 & Circulatory system & 142 & 396 & 35.9 \\
\hline Chapter 10 & j & Respiratory system & 76 & 233 & 32.6 \\
\hline Chapter II & $\mathrm{K}$ & Digestive system & 263 & 455 & 57.8 \\
\hline Chapter 12 & $\mathrm{~L}$ & Skin & 115 & 348 & 33.0 \\
\hline Chapter 13 & M & Musculoskeletal system & 2031 & 3361 & 60.4 \\
\hline Chapter 14 & $\mathrm{~N}$ & Genitourinary system & 207 & 435 & 47.6 \\
\hline Chapter I5 & 0 & Pregnancy \& childbirth & 139 & 436 & 31.9 \\
\hline Chapter 16 & $P$ & Perinatal & 115 & 366 & 31.4 \\
\hline Chapter 17 & Q & Congenital abnormalities & 887 & 887 & 100.0 \\
\hline Chapter 18 & $\mathrm{R}$ & Symptoms NEC & 6 & 334 & 1.8 \\
\hline Chapter 19 & $\mathrm{~S} / \mathrm{T}$ & Injuries & 44 & 1785 & 2.5 \\
\hline Chapter 20 & U-Y & External causes' of morbidity & 1508 & 2905 & 51.9 \\
\hline Chapter 21 & $\mathrm{Z}$ & Factors influencing health status & 638 & 684 & 93.3 \\
\hline \multirow[t]{2}{*}{ Appendix A } & & Morphology of neoplasms & 2408 & 2408 & 100.0 \\
\hline & & Total & 10411 & 18418 & 56.5 \\
\hline
\end{tabular}

Table 3: Uncertainty* in condition-onset flagging eligibility by ICD-10 Chapter

\begin{tabular}{|c|c|c|c|c|c|}
\hline Chapter & Code group & & Frequency of codes with high uncertainty & $\begin{array}{r}\mathbf{N} \text { of } \\
\text { codes in chapter }\end{array}$ & $\%$ \\
\hline Chapter I & $A B$ & Infectious and parasitic disease & 138 & 766 & 18.0 \\
\hline Chapter 2 & $C / D$ & Neoplasms & 0 & 790 & 0.0 \\
\hline Chapter 3 & part D & Anaemia \& other blood diseases & 30 & 164 & 18.3 \\
\hline Chapter 4 & $\mathrm{E}$ & Endocrine & 74 & 458 & 16.2 \\
\hline Chapter 5 & $\mathrm{~F}$ & Mental/behavioural & 43 & 448 & 9.6 \\
\hline Chapter 6 & G & Nervous system & 66 & 387 & 17.1 \\
\hline Chapter $7 / 8$ & $\mathrm{H}$ & Eye \& ear & 36 & 372 & 9.7 \\
\hline Chapter 9 & I & Circulatory system & 23 & 396 & 5.8 \\
\hline Chapter 10 & $J$ & Respiratory system & 4 & 233 & 1.7 \\
\hline Chapter II & $\mathrm{K}$ & Digestive system & 23 & 455 & 5.1 \\
\hline Chapter 12 & $\mathrm{~L}$ & Skin & 58 & 348 & 16.7 \\
\hline Chapter 13 & M & Musculoskeletal system & 264 & 3361 & 7.9 \\
\hline Chapter 14 & $N$ & Genitourinary system & 49 & 435 & 11.3 \\
\hline Chapter 15 & 0 & Pregnancy \& childbirth & 60 & 436 & 13.8 \\
\hline Chapter 16 & $P$ & Perinatal & 0 & 366 & 0.0 \\
\hline Chapter 17 & $\mathrm{Q}$ & Congenital abnormalities & 0 & 887 & 0.0 \\
\hline Chapter 18 & $\mathrm{R}$ & Symptoms NEC & 0 & 334 & 0.0 \\
\hline Chapter 19 & ST & Injuries & 64 & 1785 & 3.6 \\
\hline Chapter 20 & U-Y & External causes of morbidity & 275 & 2905 & 9.5 \\
\hline Chapter 21 & Z & Factors influencing health status & 16 & 684 & 2.3 \\
\hline \multirow[t]{2}{*}{ Appendix A } & & Morphology of neoplasms & 0 & 2408 & 0.0 \\
\hline & & Total & 1223 & 18418 & 6.6 \\
\hline
\end{tabular}

*'Uncertainty' defined as $<2$ reviewers making a positive (valid) or negative (invalid) recommendation. 
Table 4 displays the effects of our audit algorithm on code flag status and code-use counts. Victorian coders in 20052006 used only 4,345 of the possible 18,418 available ICD-10-AM codes for C-flagged fields $(23.6 \%)$. Of the codes flagged, $68.0 \%$ were determined to be valid using the algorithm, an additional $8.2 \%$ of flagged codes would have generated a 'warning' (potentially valid), for a total of $76.2 \%$ acceptable code choice. Invalid codes were $23.8 \%$ of all individual codes flagged, but of these, $42.0 \%$ ( $\mathrm{n}=433$ codes) were used only once in the data set, and $76.5 \%(\mathrm{n}=789$ codes $)$ used in fewer than 5 instances.

When the number of times a code is used is taken into account, the acceptable coding rate is raised to $96.14 \%$ (93.9\% valid plus $2.3 \%$ 'warning'). Invalid prefixing thus affected $3.9 \%$ of the 386,048 diagnoses flagged as 'notPOA' in these 2 million records.

Table 5 breaks down problematic flagging by ICD Chapter. The invalid assignment of the C-prefix/flag by Victorian coders was concentrated in chapters relating to the cardiovascular system $(28.5 \%)$, the endocrine system $(16.0 \%)$, the genitourinary system $(10.4 \%)$ and factors influencing health status $(12.2 \%)$. In the cardiovascular case, nearly three-quarters of the invalid flagging was for a single code: I10 Essential (primary) hypertension.

Flagging of codes relating to factors influencing health status (Chapter 21 of the ICD) reflected considerable confusion, with roughly $20 \%$ of invalid codes due to 'hospitalacquired' palliative care and another $20 \%$ flagged codes for cancelled procedures. The endocrine system chapter was a large contributor to both invalid flagging and the assignment of the C-prefix/flag to 'warning' codes, representing $16 \%$ of the invalids, and $55 \%$ of the warnings. In the genitourinary system codes, two-thirds of invalidly flagged cases related to codes for chronic renal failure. The particular issue of acute problems in the context of underlying chronic diseases such as diabetes and renal failure are discussed below, and give rise to much of the confu-

Table 4: Number of invalid condition onset flags assigned in the Victorian Admitted Episodes Dataset, 2005/06

\begin{tabular}{lrrr}
\hline & $\mathbf{N}$ & \% Total & \% Flagged \\
\cline { 2 - 4 } & & & \\
Total available ICD-I0-AM codes & 18418 & $100.0 \%$ & \\
Individual codes C-prefixed & 4345 & $23.6 \%$ & $100.0 \%$ \\
$\quad$ Valid codes & 2956 & $16.0 \%$ & $68.0 \%$ \\
$\quad$ Warning codes flagged & 357 & $1.9 \%$ & $8.2 \%$ \\
$\quad$ Invalid codes flagged & 1032 & $5.6 \%$ & $23.8 \%$ \\
& & & \\
Cases of validly flagged codes & 362350 & $93.9 \%$ & \\
Cases of flagged warning codes & 8800 & $2.3 \%$ & $96.14 \%$ \\
Cases of invalidly flagged codes & 14898 & $3.9 \%$ & \\
Total cases of C-prefixing & 386048 & $100.0 \%$ & \\
\hline
\end{tabular}

sion in the endocrine and genitourinary chapters of the ICD.

\section{Discussion}

There are many conditions that are unlikely to be hospital-acquired, that is, when detected during a hospital episode, they would inevitably have been present on admission. Our panel of health information managers, supplemented by specialist clinician review, identified 10,567 of the codes in the Australian version of the International Classification of Diseases as unlikely to be hospital-acquired.

When the 2,408 Australian codes used to characterise the morphology of various cancer diagnoses are removed, this results in 8159 diagnosis codes classed as invalid in our algorithm, compared with the current Canadian edit that uses only 962 codes. Comparison with US guidelines for the POA flag is more difficult because the US continues to use the previous version of the ICD (ICD-9-CM).

While the algorithm reported here nominates over half the possible diagnoses as invalid for flagging as hospitalacquired, actual Victorian coding reflects a high degree of selectivity in assigning the C-prefix. Acceptable flagging of diagnosis codes was found in $96.14 \%$ of uses in a single year's data. These findings give us confidence in taking a conservative approach to rejecting flagged diagnoses, 'conservative' in the sense of preserving information in the data by defaulting to 'warning' codes.

The patterns of use of invalid and warning codes demonstrated that random error (reflected in single-case misuse) was quite small in comparison with more systematic patterns of invalid flagging. This suggests that revised coding standards for a small number of specific diagnosis codes would yield large improvements in the remaining $3.9 \%$ of invalid flag use.

The largest number of invalid flag assignments arose from codes which represent two concepts in a single code. Typical of these codes is E10.64 Type 1 diabetes mellitus with hypoglycaemia. Victorian prefixing/flagging rules include a hierarchy which mandates that the $\mathrm{P}$ (primary) prefix/flag take precedence over a $\mathrm{C}$ prefix/flag when a code contains two concepts (one existing on admission, one being a complication). By making these codes invalid for a $\mathrm{C}$ flag, there is a risk that poor diabetes management in hospital, for example, will not be detected. Changing the precedence rule, however, risks over-identifying hospitalacquired complications which would also be undesirable. Resolution of ambiguities in these combined codes is a priority for classification development.

The coding convention of adding a second code to fully describe the 'medical statement' allows for the 'complica- 
Table 5: Flagging of 'warning' and invalid codes by ICD Chapter in the Victorian Admitted Episodes Dataset, 2005/06

\begin{tabular}{|c|c|c|c|c|c|c|}
\hline \multirow[b]{2}{*}{ Chapter } & & & \multicolumn{2}{|c|}{ Invalid flagging } & \multicolumn{2}{|c|}{ Warning flagging } \\
\hline & & & $\mathbf{N}$ & $\%$ Invalid & $\mathbf{N}$ & $\%$ Warning \\
\hline Chapter I & $A B$ & Infectious and parasitic disease & 207 & $1.4 \%$ & II & $0.1 \%$ \\
\hline Chapter 2 & $C / D$ & Neoplasms & 258 & $1.7 \%$ & 0 & $0.0 \%$ \\
\hline Chapter 3 & part $D$ & Anaemia \& other blood diseases & 40 & $0.3 \%$ & 66 & $0.8 \%$ \\
\hline Chapter 4 & $E$ & Endocrine & 2389 & $16.0 \%$ & 4854 & $55.2 \%$ \\
\hline Chapter 5 & $\mathrm{~F}$ & Mental/behavioural & 262 & $1.8 \%$ & 477 & $5.4 \%$ \\
\hline Chapter 6 & G & Nervous system & 199 & $1.3 \%$ & 184 & $2.1 \%$ \\
\hline Chapter $7 / 8$ & $\mathrm{H}$ & Eye \& ear & 174 & $1.2 \%$ & 64 & $0.7 \%$ \\
\hline Chapter 9 & 1 & Circulatory system & 4242 & $28.5 \%$ & 1068 & $12.1 \%$ \\
\hline Chapter 10 & J & Respiratory system & 641 & $4.3 \%$ & 20 & $0.2 \%$ \\
\hline Chapter II & $\mathrm{K}$ & Digestive system & 1370 & $9.2 \%$ & 165 & $1.9 \%$ \\
\hline Chapter 12 & $\mathrm{~L}$ & Skin & 204 & $1.4 \%$ & 243 & $2.8 \%$ \\
\hline Chapter 13 & $M$ & Musculoskeletal system & 919 & $6.2 \%$ & 709 & $8.1 \%$ \\
\hline Chapter I4 & $\mathrm{N}$ & Genitourinary system & 1542 & $10.4 \%$ & 610 & $6.9 \%$ \\
\hline Chapter 15 & O & Pregnancy \& childbirth & 13 & $0.1 \%$ & 5 & $0.1 \%$ \\
\hline Chapter 16 & $\mathrm{P}$ & Perinatal & 39 & $0.3 \%$ & 14 & $0.2 \%$ \\
\hline Chapter 17 & $\mathrm{Q}$ & Congenital abnormalities & 26 & $0.2 \%$ & 0 & $0.0 \%$ \\
\hline Chapter 18 & $\mathrm{R}$ & Symptoms NEC & 20 & $0.1 \%$ & 0 & $0.0 \%$ \\
\hline Chapter 19 & ST & Injuries & 2 & $0.0 \%$ & 15 & $0.2 \%$ \\
\hline Chapter 20 & U-Y & 'External causes' of morbidity & 535 & $3.6 \%$ & 138 & $1.6 \%$ \\
\hline Chapter 21 & $\mathrm{Z}$ & Factors influencing health status & 1815 & $12.2 \%$ & 157 & $1.8 \%$ \\
\hline \multirow[t]{2}{*}{ Appendix A } & & Morphology of neoplasms & 1 & $0.0 \%$ & 0 & $0.0 \%$ \\
\hline & & & 14898 & $100.0 \%$ & 8800 & $100.0 \%$ \\
\hline
\end{tabular}

tion' to be coded separately and flagged with C; diabetes with acute renal failure is the best example. Diabetes would be coded to E10.29 Diabetes with other specified renal complications, and a second code, N17.9 Acute renal failure would be added for the renal complication. Knowledge about areas where such uncertainty exists in the classification can make condition-onset flagging more reliable, and form the basis for better training of coders in recording this valuable information.

The intellectual task of determining which codes may be used legitimately with a 'complications' flag may be compared with that of clinical diagnosis: there will be false positive and false negative assignments, as well as accurately positive and negative ones. False negatives are a well-known limitation of the use of routine hospital data for patient safety research [35]. When medical doctors reviewed subsets of included codes for a parallel project, they recommended more exclusions than our HIM reviewers, who had either disagreed or indicated uncertainty. Of our three reviewers, one had a higher propensity to assign an 'uncertain' status to codes than the other two HIM reviewers, resulting in a slightly lower Kappa value (.61) than desirable. Recognising that many of the codes were split $2 / 1$, where the single reviewer had assigned the conservative 'warning' status, the research team decided that 2 negative recommendations was adequate as the basis for the exclusion algorithm.
We envisage the tool reported here to be subject to ongoing refinement. In particular, prior to $1^{\text {st }}$ July 2007 , condition onset was difficult for coders to judge for maternity diagnoses. The Victorian Additions to the Australian Coding Standards [36] changed frequently between the years 2000 and 2007. From 2000 to mid-2004 a limited number of obstetric conditions were permitted to be ' $\mathrm{C}$ '

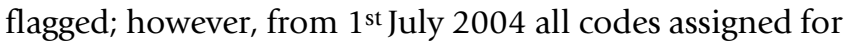
an obstetric episode were directed to be flagged as primary diagnoses, implying they were present on admission. This changed again in July 2006 when conditions or injuries arising after the second stage of labour were considered to be 'complication' diagnoses, that is, arising after the 'admission' of the patient and could be flagged as hospital-acquired.

In practice, coders generally assigned a ' $\mathrm{P}$ ' (primary) flag to all intrapartum events because of the difficulty of discerning causation by stage of labour. From July 2007 additional instructions for the flagging of obstetric episodes were abandoned and currently obstetric episodes are treated the same as all other episodes of care.

Similar anomalies arise when dealing with neonatal diagnoses. Current definitions for the 'admission' of newborns create difficulties in the assignment of a complications flag for events causing injury to newborns in hospital but occurring before birth, the point at which they are deemed to be 'admitted'. When data are used for the screening of adverse events, additional analysis will be 
required to extract 'primary' diagnoses for neonatal episodes.

Many diagnoses develop over extended time periods, but are not 'chronic' in nature, and additional work may be required to identify which of these conditions might plausibly be hospital-acquired, and over what time scale. One trivial example that arose was whether L600 Ingrowing nail, could ever be 'hospital-acquired'. It is assigned 'warning' status, on the reasoning that long stay patients without access to podiatry might develop the condition, rather than being admitted with it. Some 'warning' codes might in future be linked with information on length of stay to better judge the validity of their flagging.

Special consideration was also given to infectious diseases that are typically 'community acquired'. Clinical advisors queried the inclusion of water-borne diseases such as A071 Giardiasis and A072 Cryptosporidiosis. It was agreed that, although uncommon, these infections could be acquired in a hospital with a compromised water supply, and should be available to coders when documentation showed this to be the case.

The presumption is that most psychiatric conditions will have developed over a period of time prior to hospital admission. However, some medications can give rise to psychiatric symptoms, and hospital care is sometimes itself traumatic. In addition, inappropriate management of drug and alcohol dependence could also give rise to hospital-acquired diagnoses in Chapter 5 of the ICD.

\section{Conclusion}

Indicator variables about the timing of occurrence of diagnoses (pre-existing on hospital admission $v s$ newly acquired in a hospital episode) are being introduced in health systems around the world. They can greatly expand the use of routine diagnosis coding for hospital and health system quality improvement programmes.

The data cleaning instrument developed and tested here can help guide coding practice in those health systems introducing this change in hospital coding. It will also be a useful tool for researchers using flagged data to reduce random error in flagging and to target systematic error.

Coding in one Australian state with over 20 years' experience using the flag reflects very high use of valid codes as determined using this algorithm. Revised coding standards and additional coder education would improve data validity for routine use of flagged diagnoses in quality assurance efforts.

\section{Competing interests}

The authors declare that they have no competing interests.

\section{Authors' contributions}

TJJ, as guarantor of this manuscript, was involved in all aspects of the conduct of the research. JLM, RR, JS, JR and DC served as expert reviewers for all or parts of the ICD; $\mathrm{CP}$ had the original idea for the study and conducted an earlier pilot of the methods. TJJ and JLM conducted the literature search and drafted the paper; all authors reviewed the manuscript and contributed comments and revisions.

\section{Additional material}

\section{Additional file 1}

Validation algorithm for 'Present on Admission' (POA) flagging written for $S A S^{\mathrm{TM}}$ processing. This $S A S^{\mathrm{TM}}$ program evaluates 40 diagnosis fields in routinely coded hospital data to identify those validly flagged as hospital-acquired (' $\mathrm{C}$ ' in the data used here). Codes refer to the International Statistical Classification of Diseases and Related Health Problems, Tenth Revision, Australian Modification (ICD-10-AM). Fourth ed. Sydney: National Centre for Classification in Health, The University of Sydney; 2004. See Additional file 2 for further information on the programming.

Click here for file

[http://www.biomedcentral.com/content/supplementary/14726947-9-48-S1.DOC]

\section{Additional file 2}

Instructions for data cleaning algorithm 20090304. This document includes additional information for use of the data cleaning algorithm. Click here for file

[http://www.biomedcentral.com/content/supplementary/14726947-9-48-S2.DOC]

\section{Acknowledgements}

The authors are grateful to the Victorian Department of Health for access to the Victorian Admitted Episodes Dataset. The Australian Commission on Safety and Quality in Health Care provided support for this project. All views expressed are those of the authors, and do not represent the policy of the Australian Commission on Safety and Quality in Health Care, or those of the Victorian Department of Health. We are grateful to Drs Christine Jorm, John Wakefield and Olafr Steinum, clinical advisors on a parallel research project, for additional clinical review of some code subsets, and to Dr H.S. Nghiem for assistance with programming.

\section{References}

I. The Centers for Medicare \& Medicaid Services: Present on Admission Indicator. In MLN Matters Baltimore, MD: The Centers for Medicare \& Medicaid Services; 2007.

2. Naessens JM, Brennan MD, Boberg C], Amadio PC, Karver PJ, Podratz RO: Acquired conditions: an improvement to hospital discharge abstracts. Qual Assur Health Care 1991, 3:257-262.

3. Coffey R, Milenkovic M, Andrews RM: The case for the Presenton-Admission (POA) indicator. In HCUP Methods Series Report \#2006-0I U.S. Agency for Healthcare Research and Quality; 2006.

4. The Centers for Medicare \& Medicaid Services: Hospitals exempt from Present on Admission (POA) reporting (i.e. non-inpatient Prospective Payment System (IPPS) hospitals) and the grouper. In MLN Matters Baltimore, MD: The Centers for Medicare \& Medicaid Services; 2008.

5. Bates DW, Evans RS, Murff H, Stetson PD, Pizziferri L, Hripcsak G: Detecting adverse events using information technology. J Am Med Inform Assoc 2003, 10:115-128. 
6. Documentation Department: Definitions of Medicare code edits. Wallingford, CT: 3 M Health Information Systems; 2007.

7. Haller G, Myles PS, Stoelwinder J, Langley M, Anderson H, McNeil J: Integrating incident reporting into an electronic patient record system. J Am Med Inform Assoc 2007, 14:175-I8I.

8. Hargreaves J: Reporting of adverse events in routinely collected data sets in Australia. In Health Division Working Paper no 3 Canberra: Australian Institute of Health and Welfare; $200 \mathrm{I}$

9. Hogan H, Olsen S, Scobie S, Chapman E, Sachs R, McKee M, Vincent $C$, Thomson R: What can we learn about patient safety from information sources within an acute hospital: a step on the ladder of integrated risk management? Qual Saf Health Care 2008, I 7:209-2I5.

10. lezzoni Ll: Assessing quality using administrative data. Ann Intern Med 1997, I 27:666-674.

II. Naessens JM, Scott CG, Huschka TR, Schutt DC: Do complication screening programs detect complications present at admission? It Comm J Qual Saf 2004, 30: I33-I42.

12. Glance LG, Dick AW, Osler TM, Mukamel DB: Does date stamping ICD-9-CM codes increase the value of clinical information in administrative data? Health Serv Res 2006, 4I:23I-25I.

13. Glance LG, Dick AW, Osler TM, Mukamel DB: Accuracy of hospital report cards based on administrative data. Health Serv Res 2006, 4I: |4|3-|437.

14. Glance LG, Osler TM, Mukamel DB, Dick AW: Impact of the present-on-admission indicator on hospital quality measurement. Med Care 2008, 46:1 I2-119.

15. Pine M, Jordan HS, Elixhauser A, Fry DE, Hoaglin DC, Jones B, Meimban R, Warner D, Gonzales J: Enhancement of claims data to improve risk adjustment of hospital mortality. JAMA 2007, 297:7I-76.

16. Zhan C, Elixhauser A, Friedman B, Houchens R, Chiang Y-p: Modifying DRG-PPS to include only diagnoses present on admission: financial implications and challenges. Med Care 2007 45:288-29I.

17. Naessens JM, Huschka TR: Distinguishing hospital complications of care from pre-existing conditions. Int J Qual Health Care 2004, 16:i27-35.

18. Houchens RL, Elixhauser A, Romano PS: How often are potential patient safety events present on admission? Jt Comm J Qual Patient Saf 2008, 34:154-163.

19. Victorian Additions to Australian Coding Standards: Vic Prefixes [http://www.health.vic.gov.au/hdss/icdcoding/vicadditions/ vicadd05.pdf]

20. Jackson T, Duckett S, Shepheard I, Baxter K: Measurement of adverse events using 'incidence flagged' diagnosis codes. J Health Serv Res Policy 2006, I I:21-25.

21. National Centre for Classification in Health: ACS 0048 Condition onset flag. In Australian Coding Standards Six edition. Sydney: The University of Sydney; 2008.

22. The Centers for Medicare \& Medicaid Services (CMS) \& National Center for Health Statistics (NCHS): ICD-9-CM official guidelines for coding and reporting. Appendix I: Present on Admission Reporting Guidelines; 2008.

23. Canadian Institute for Health Information (CIHI): Canadian coding standards for ICD-I 0-CA and CCI for 2007. Ottawa: Canadian Institute for Health Information (CIHI); 2007.

24. Canadian Institute for Health Information (CIHI): DAD Abstracting Manual (for use with ICD-I0-CA/CCI). 2007-2008 edn Ottawa: Canadian Institute for Health Information; 2007.

25. ICD-I0-CA Page.jsp?cw page $=$ codingclass icd 10 e CM codes in hospital morbidity data, Victoria: implications for public health research. Aust N Z J Public Health 1997, 2I:477-482.

27. Henderson T, Shepheard J, Sundararajan V: Quality of diagnosis and procedure coding in ICD-10 administrative data. Med Care 2006, 44:1011-1019.

28. Audits of Hospital Admitted Patient Data 2005-08, In ICD Coding Newsletter: First quarter 2006-07 Melbourne, Vic: Victorian Government Department of Human Services; 2006:15-18.

29. Perry C, McNair P: Are prefixes important? The undervalued data item! Victorian ICD Coding Newsletter 2004:9-II.
30. Health Data Standards and Systems Unit [HDSS]: VAED 18th edition user manual 2008-09: Section 8 - editing. Health Data Standards \& Systems Unit, Department of Human Services; 2008.

31. Kilbridge PM, Classen DC: The informatics opportunities at the intersection of patient safety and clinical informatics. J Am Med Inform Assoc 2008, I5:397-407.

32. National Centre for Classification in Health: International Statistical Classification of Diseases and Related Health Problems, Tenth Revision, Australian Modification (ICD-IO-AM) Fourth edition. Sydney: The University of Sydney; 2004

33. Randolph Jj: Online Kappa Calculator 2008 [http://justus.ran dolph.name/kappa]. Retrieved July 24, 2009

34. Jackson TJ, Michel JL, Roberts RF, Jorm CM, Wakefield JG: A classification of hospital-acquired diagnoses for use with routine hospital data. Med J Aust 2009, I9I(I0):

35. Quan H, Parsons GA, Ghali WA: Assessing accuracy of diagnosis-type indicators for flagging complications in administrative data. / Clin Epidemiol 2004, 57:366-72.

36. Victorian Additions to Australian Coding Standards [http:// www.health.vic.gov.au/hdss/icdcoding/vicadditions/index.htm]

\section{Pre-publication history}

The pre-publication history for this paper can be accessed here:

http://www.biomedcentral.com/1472-6947/9/48/prepub
Publish with Bio Med Central and every scientist can read your work free of charge

"BioMed Central will be the most significant development for disseminating the results of biomedical research in our lifetime. "

Sir Paul Nurse, Cancer Research UK

Your research papers will be:

- available free of charge to the entire biomedical community

- peer reviewed and published immediately upon acceptance

- cited in PubMed and archived on PubMed Central

- yours - you keep the copyright

Submit your manuscript here:

http://www.biomedcentral.com/info/publishing_adv.asp
BioMedcentral 